\title{
Ensuring health graduates' employability in a changing world: Developing interprofessional practice capabilities using a framework to inform curricula
}

\author{
Margo Brewer ${ }^{1}$, Helen Flavell ${ }^{1}$, Courtney Harris ${ }^{1}$, Melissa Davis ${ }^{1}$, Katherine Bathgate ${ }^{1}$ \\ M.Brewer@curtin.edu.au; H.Flavell@curtin.edu.au; C.Harris@curtin.edu.au; \\ m.davis@curtin.edu.au; K.Bathgate@curtin.edu.au \\ ${ }^{1}$ Curtin University
}

\begin{abstract}
Curtin University introduced an interprofessional first year curriculum in the Faculty of Health Sciences in 2011. This curriculum, now delivered to over 3,300 first year health science students annually, consists of five common compulsory units, eight optional units (specific to several courses) and one discipline specific unit for each course. Significantly, the learning outcomes are informed by an Interprofessional Capability Framework (Brewer \& Jones, 2013). This paper reports on a study which aimed to analyse the use of the capability framework in supporting the development of the desired interprofessional capabilities.

This qualitative study was based on data from student reflective journals in one of the large common units. The sample consisted of 105 of the 411 students enrolled in one of the common units (response rate 25.6 percent) in the second major teaching period (semester two) in 2011. The data was analysed via NVivo ${ }^{\odot}$ to provide a holistic view of the content of the reflections as they related to the Interprofessional Capability Framework. The results indicate that the use of the Interprofessional Capability Framework in structuring the learning outcomes has influenced student learning. This is evidenced by the correlation between the themes which emerged during the coding of the data and the Interprofessional Capability Framework. For example, 'Client-centred' was the most frequently coded theme, followed by Collaboration, Team Function, and Quality Care, all of which are reflected in the Framework. The major finding of the study is that the framework did have an impact in guiding the development of the foundational interprofessional unit; the learning outcomes included key elements of the framework, the learning experiences were designed to meet these outcomes, and the assessment utilising a reflective journal was designed to measure the development of novice interprofessional capabilities.
\end{abstract}

Keywords: curriculum framework, interprofessional, graduate capabilities, constructive alignment

\section{Introduction}

Graduate employability has, for some time, been core business for higher education and is often manifested through the identification of generic key graduate attributes (Barrie, 2012; Bridgstock, 2009). However, the extent to which graduate outcomes are achieved is uncertain particularly in the area of generic outcomes as measuring graduate abilities is difficult, time-consuming and, in some cases, impossible (Oliver, 2011). Additionally, many 
academics lack a shared understanding of what is meant by graduate attributes (Barrie, 2012) and the confidence to teach generic capabilities, instead preferring their own disciplinary content (de la Harpe et al., 2009). Despite these challenges and complexities, there is growing emphasis worldwide on demonstrating student learning outcomes with universities increasingly scrutinised by quality assurance organisations (Krause, Barrie, Scott, Sachs \& Probert, 2012).

In the education of health professionals there are parallel pressures to ensure that graduates have not only their discipline specific knowledge, but also generic capabilities which will enable health services to meet the demands of future health and social care needs. The World Health Organization (WHO), for example, argues that due to changes in population demographics there is a growing need for graduates with the capabilities to work collaboratively in interprofessional teams to deliver high quality, safe client care (World Health Organisation, 2010). Interprofessional education has been identified as the mechanism to prepare graduates who can demonstrate these interprofessional collaborative capabilities and has been defined by the WHO as occur[ing] when students from two or more professions learn about, from and with each other to enable effective collaboration and improve health outcomes (2010).

There is considerable debate and contestation regarding graduate outcome terminology including, for example, competency versus capability and how graduate attributes and employability are defined (Barrie, 2012; Eraut, 1998; Stephenson, 1994). However, Yorke's conceptualisation of graduate attributes is well accepted as it portrays a complex set of integrated skills, characteristics and abilities that aid employability. Yorke defines graduate attributes as the skills, understandings and personal attributes that make an individual more likely to secure employment and be successful in their chosen occupations to the benefit of themselves, the workforce, the community and the economy (Yorke, 2006, p. 8). His definition of 'graduate attributes' is particularly pertinent to the field of interprofessional education as he clearly links the development of graduate outcomes with workforce and community needs, a major focus of interprofessional education. Health workers who are better prepared to work collaboratively with other health professionals-with a focus on client needs rather than the goals of the professional-are more likely to impact positively on client outcomes (Barrett, Curran, Glynn \& Godwin, 2007). Interprofessional capabilities, therefore, extend well beyond discipline knowledge and understanding. The capabilities identified for an effective interprofessional health worker including communication, reflective skills, team function, conflict resolution and client-centred care (Barr, 1998; Walsh, Gordon, Marshall, Wilson \& Hunt, 2005; Wood, Flavell, Vanstolk, Bainbridge \& Nasmith, 2009), align well with the vision of an employable graduate needing a sophisticated, integrated set of capabilities that encompass more than discipline specific knowledge, skills and understandings.

\section{Interprofessional Education}

Interprofessional education has emerged as an area of focus in higher education for many reasons including the need to modify negative attitudes and perceptions, and to redress issues of trust and communication between professions (Carpenter, 1995). Barr (2002) hypothesised that pre-licensure interprofessional education might have both a preventative function (mitigating the risk of developing prejudices and negative stereotypes) and a preparatory function (laying the foundation for subsequent interprofessional learning and practice). Early introduction of regular and sustained interprofessional education continues to find support one decade on (Reeves, Tassone, Parker, Wagner, \& Simmons, 2012). In keeping with this, and the desire to deliver the practice-ready health workers of the future, Curtin University introduced an interprofessional first year curriculum in the Faculty of Health Sciences in 2011. This curriculum, delivered now to over 3,300 first year health science students annually, consists of five common compulsory units, eight optional units (specific to several courses) and one discipline specific unit for each course. This curriculum ensures 
that 75 percent of first year student learning experiences have an element of interprofessional education. This is most explicit in the common units which are taught by interprofessional teaching teams to interprofessional student groups (Bathgate \& Harris, 2012). Significantly, the learning outcomes of the common first year units (as well as other interprofessional education experiences offered by the Faculty) are informed by an interprofessional capability framework (Brewer \& Jones, 2013). This paper presents qualitative data from the analysis of student reflective journals in one of the large common interprofessional first year units to demonstrate how the use of a capability framework to inform the curriculum design is supporting students in the development of the interprofessional graduate capabilities deemed essential for future health workers. Utilising Knight and Yorke's (2002) USEM model of employability-as a set of capabilities which extend beyond skills and knowledge-the paper illustrates how the unit learning outcomes, which are in alignment with the framework, are supporting first year students to develop crucial interprofessional graduate attributes. In fact, qualitative data analysis suggests there is evidence that first year students are demonstrating what Knight and Yorke identify as 'efficacy beliefs and metacognition' at the novice level (as defined by the Interprofessional Capability Framework). The study adds to the body of literature on interprofessional education and, more specifically, contributes to the limited evaluative research on the implementation of interprofessional frameworks (Reeves, Zwarenstein, Goldman, Barr, Freeth, Koppel \& Hammick, 2010).

\section{Knight and Yorke's (2002) USEM Model of Graduate Employability}

Knight and Yorke's USEM model was developed based on 'capability' as defined by Stephenson, as well as the literature on employability and insights from cognitive and social psychology (Knight \& Yorke, 2002, p. 264). According to Stephenson (1998), capability is a necessary part of specialist expertise, not separate from it. Capable people not only know about their specialisms, they also have confidence to apply their knowledge and skills within varied and changing situations and to continue to develop their specialist knowledge and skills... (cited in Knight \& Yorke, 2002, p. 264). In other words, capability in this context implies that graduates with the capabilities that count for employability know much more than their discipline or specialist knowledge, they are able to effectively manage changing circumstances and respond appropriately.

USEM (Knight \& Yorke, 2002, p. 264) is an acronym which represents a complex and rich theory of graduate employability and stands for:

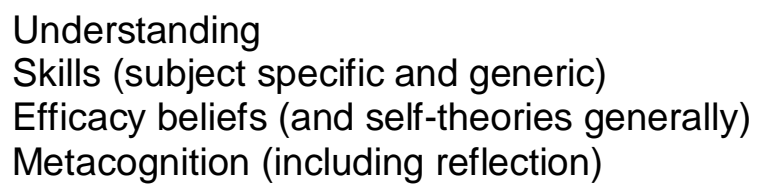

According to the authors, curricula have a tendency to focus on Understanding and Skills with little attention to personal qualities or Efficacy beliefs and Metacognition. This appears consistent with research into graduate attributes which suggests most Australian universities struggle to effectively embed the generic capabilities implied by graduate attributes (Barrie, Hughes \& Smith, 2009). In keeping with the theory of interprofessional education (Barr, 2012; Colyer, Helme \& Jones, 2005; Hean, Craddock \& Hammick, 2012), Knight and Yorke argue that students' personal qualities (including self-theories and efficacy beliefs) colour everything the student/graduate does. Their model, therefore, takes into account the impact of personal qualities and beliefs on student learning. This approach to graduate capability and employability is highly applicable to an interprofessional education context, where professional identity and role understanding have the capacity to significantly hinder or facilitate the development of interprofessional collaborative practice capabilities (Coster, Norman, Murrells, Kitchen, Meerabeau, Sooboodoo \& d'Avrey 2008; Forte \& Fowler, 2009; 
Wackerhausen, 2009). As will be illustrated, the Interprofessional Capability Framework used to inform the common interprofessional first year units emphasises the $E$ and $M$ of Knight and Yorke's USEM Model and appears to assist first year students to begin their journey towards developing interprofessional practice capabilities. These capabilities align well with many of the 'soft' generic attributes desired for all university graduates including communication, teamwork, critical reflection and conflict resolution (Precision Consulting, 2007).

\section{The Interprofessional Capability Framework}

The competency movement in interprofessional education began to gain prominence in the late 1990s (Barr, 1998). Since that time a number of lists of key interprofessional competencies and competency frameworks have been published (Bainbridge, Nasmith, Orchard \& Wood, 2010; Barr, 1998; Interprofessional Education Collaborative Expert Panel, 2011; Walsh et al., 2005; Wood et al., 2009). Such frameworks define educational outcomes based on the knowledge, skills, attitudes and values underpinning the competencies for practice (Curran et al., 2008). The movement to competency based education is not without its critics. Reeves, Fox \& Hodges (2009) raised concerns about not only the process for developing such frameworks, but also the need to be cautious in their implementation as they shape education, regulation and practice. At the same time, there is inconsistency within the movement towards frameworks with debate about the value of competencies versus capabilities. Competence can be defined as the habitual and judicious use of communication, knowledge, technical skills, clinical reasoning, emotions, values and reflection in daily practice for the benefit of the individual and community served (Epstein \& Hundert, 2002, p. 226). Capability on the other hand refers to the ability to change, generate knowledge and continuously improve performance (McNair, 2005, p. 460). As capability infers ongoing adaption (Cooper, Spencer-Dawe \& McLean, 2005) it was utilised in Curtin's framework (Brewer, 2011, p. 5) which operates with several assumptions including:

- Collaborative practice is critical to client safety and quality of service or care;

- Interprofessional education occurs on a continuum from early exposure to other professions through to collaborative practice in teams in the practice setting;

- The learner will move through the levels at different rates according to their personal and professional experiences;

- A student's capacity to demonstrate interprofessional capabilities in different settings will be impacted by their comfort level, familiarity and skill set within that context.

The framework consists of three core elements: client-centred service, client safety and quality, and collaborative practice; which are underpinned by five interprofessional practice capabilities: communication, team function, role clarification, conflict resolution and reflection (see Table 1).

The practice capabilities are interdependent and developmental on a three phase continuum: novice, intermediate and entry to practice. Key terminology in the framework is viewed with a broad understanding to ensure a high level of inclusivity. Significantly, the use of 'client' rather than 'patient' was the result of the Interprofessional Capability Framework needing to speak to a broad range of health science professions where, in some instances, 'patient' was not appropriate. The term 'client' includes the family and the community and 'safety' includes the physical, psychological, environmental and cultural aspects of health care. Thus the focus on client-centred care is strongly related to safety and quality and supports the provision of culturally responsive service delivery through emphasising client needs over the health professional's interests and needs.

The framework is provided in the form of a booklet to all students and teaching staff within the interprofessional first year units. The booklet provides key background information, 
definitions, the underlying assumptions, an overview of each element along with a set of descriptors and capabilities at each level. The capability framework provided staff with an opportunity to design learning experiences that emphasise observable abilities that can be assessed in terms of development milestones (Frank, Mungroo, Ahmad, Wang, de Rossi \& Horsley, 2010).

\section{Table 1: Curtin University's Faculty of Health Sciences IPE Curriculum Model}

\begin{tabular}{|c|c|c|c|}
\hline \multicolumn{2}{|c|}{ Interprofessional Capability Framework } & \multicolumn{2}{|l|}{ Vision } \\
\hline & & $\begin{array}{l}\text { To provide high quality } \\
\text { education experiences that } \\
\text { health science graduates have t } \\
\text { practice capabilities to deliver } \\
\text { health services }\end{array}$ & $\begin{array}{l}\text { erprofessional } \\
\text { sure Curtin's } \\
\text { collaborative } \\
\text { afe, effective }\end{array}$ \\
\hline Authenticity & Level & Learning Experiences & Complexity \\
\hline High & Entry & $\begin{array}{l}\text { Fieldwork placements } \\
\text { Case-based workshops }\end{array}$ & High \\
\hline Medium & Intermediate & $\begin{array}{l}\text { Case-based workshops and } \\
\text { simulation } \\
\text { Interprofessional focus in } \\
\text { profession specific units }\end{array}$ & Medium \\
\hline Low & Novice & Interprofessional first year & Low \\
\hline
\end{tabular}

\section{Context of the Study: Foundations for Professional Health Practice}

Foundations for Professional Health Practice is one of the five common units in Curtin's interprofessional first year curriculum which was informed by the Interprofessional Capability Framework. The unit was designed by an interprofessional team from across the Faculty of Health Sciences and aims to assist student health professionals to develop an understanding of professional practice requirements such as ethical decision making; academic standards; safety and quality of client-centred service; Australian and international health care systems, and diversity in interprofessional practice.

The unit was delivered via a weekly, three hour workshop in conjunction with online materials in a blended learning model. Each workshop comprised 50 students from different schools across the Faculty facilitated by two interprofessional tutors teaching collaboratively. Typically, students from biomedical science, nursing, midwifery, occupational therapy, pharmacy, physiotherapy, psychology, public health, social work and speech pathology would participate in the workshops. The purpose of the interprofessional teaching team was 
to model collaborative practice and provide students with an opportunity to learn 'about, from and with' teaching staff from professions other than their own.

The Foundations of Professional Health Practice curriculum, like all common first year units, was constructively aligned with the Interprofessional Capability Framework. Each week one of the three core elements or five interprofessional practice capabilities provided the theme for the learning experiences for each workshop and reflected the novice level required of first year students. In fact, all of the workshop experiences were aimed to assist students to develop interprofessional practice skills at the novice level. The capability themes would be explored through interprofessional group work activities, watching videos, YouTube clips, short podcast lectures, case studies, completing online activities, quizzes, and completion of workbook activities. Additionally, assessment tasks including oral presentations, written assignments and reflection pieces required students to use content related to the Interprofessional Capability Framework.

Consistent with the interprofessional capabilities, reflective practice was introduced within the unit with students required to reflect on their development of health professional practice capabilities as a major assessment task (worth 20 percent of the final mark). The students were required to write a 500 word reflection on their professional code of ethics, standards and obligations, and their perceptions of the value of working in interprofessional teams. Students were also required to submit with their reflection, evidence of their development of the interprofessional education core capabilities of team function, role clarification, clientcentred service, communication and conflict resolution (see Table 1).

\section{Reflective Practice}

Reflective practice is frequently described as an essential attribute of competent health care professionals (Mann, Gordon \& MacLeod, 2009). Boyd and Fales (1983) defined reflective practice as the process of internally examining and exploring an issue of concern, triggered by an experience, which reacts and clarifies meaning in terms of 'self' and which results in a changed conceptual perspective (p. 100). As with many forms of learning, reflective practice is cited as critical to effective interprofessional education and practice (Barr, 2012; Clark, 2009; Morison, Johnston \& Stevenson, 2010). The use of structured journals, selfassessment and reflective papers are considered to be effective methods to provide the necessary conditions for developing reflective skills (Clark, 2009). The ability to engage in critical reflection will facilitate graduates to develop a shared understanding of the world and ways of working together based on creating shared dialogue within communities of practice that will enhance the experience of service users (Karban \& Smith, 2006, p. 11). Much like other areas of competence or capability, reflection is a developmental process as seen in Moon's (2013) five step process from noticing to transformative learning or Findlay, Dempsey \& Warren-Forward's (2010) seven levels from non-reflector to critical reflector. The decision to include a reflective journal within Foundations for Professional Health Practice was aimed at assisting students to develop their reflective practice skills consistent with what is expected of first year (novice) students. Level 1 of reflection is outlined in the Interprofessional Capability Framework as: 'Reflects on own contributions to teamwork experiences, and reflects on own learning and progress in developing interprofessional capabilities'. The reflective journal also ensured effective assessment of the unit's learning outcome: 'Describe the key elements of ethical and professional standards and behaviours in health which impact on the safety and quality of client-centred service / care'.

\section{Method}

\section{Participants}

The sample consisted of 105 of the 411 students enrolled in Foundations of Professional Health Practice within the Faculty of Health Sciences at Curtin University (response rate 
25.6 percent) in the second major teaching period (semester two) in 2011. Students ranged in age from 17 to 51 years, with 63.8 percent of the sample aged 21 years or younger. Students represented 14 different discipline/profession areas from all of the seven Schools within the Faculty, with the majority studying either a generic Health Sciences degree (24.8 percent) or Nursing (39 percent).

\section{Materials and Procedure}

Ethics approval to conduct the research was obtained from the University's Human Research Ethics Committee and the conduct of the study was consistent with the National Health and Medical Research (2007) statement on ethical conduct of human research as well as Curtin University's policy for surveying students.

All students enrolled in the unit were invited to participate in the research via a Participant Information Sheet posted on the Learning Management System site. Students were assured that participation in the research was entirely voluntary and that their responses would be de-identified for analysis. Students provided written consent to participate in the research through submission of a signed consent form to a secure depository at the student administration centre. At the end of the semester, the written reflections of consenting students were downloaded from students' electronic portfolios by administrative staff, none of whom were involved in grading student work. No identifying information was attached to the reflections, which were imported into $\mathrm{NVivo8}^{\odot}$ to manage and organise the data (Bazeley, 2007). The data set was then analysed via NVivo8 ${ }^{\odot}$ to provide a holistic view of the content of the reflections as they related to the Interprofessional Capability Framework.

Thematic analysis (Ryan \& Bernard, 2003) was chosen to identify recurrent patterns of responses across student reflections and allow the investigators to explore the data using the Interprofessional Capability Framework that underpinned teaching and learning in this unit. The initial analysis was conducted by one investigator soon after the reflections had been submitted. The investigators took a deductive 'top-down' approach to the thematic analysis, using the Interprofessional Capability Framework as a scaffold for exploring patterns in the data (Creswell, 2012). In addition, the investigators were responsive to concepts in the students' reflections that related to, but were not covered by, the framework. An audit trail was maintained in the form of individual and group discussion notes throughout the analysis.

The investigators began by conducting several readings of each transcript in order to familiarise themselves with the data and make notes of initial impressions. The coding process involved an initial stage of open coding where each transcript was scanned for key ideas, phrases or words and codes were then collapsed into broader categories. Through a closer inspection of the categories and relationships between them, and with reference to the underlining theory, these categories were further developed and refined into overarching themes and associated subthemes (Ryan \& Bernard, 2003). Thematic maps were created to display relationships between themes and based on discussion between investigators, the interpretations of and relationships between these themes were continually modified as the data was synthesised. The number of items coded for each of the nodes in the NVivo8 ${ }^{\odot}$ analysis was also mapped in order to provide information about the most frequently occurring themes in the reflections (Bryman, 2012).

To enhance the credibility of the study, the investigators engaged in a process of peer debriefing whereby a third independent investigator selected a random 10 percent of the total codes $(n=6)$ to confirm coding strategies and interpretations. Each of the six codes was crosschecked for whether the data contained within was homogenous, whether the code name accurately represented the included data, and whether that code was appropriately situated in reference to all other codes (Bryman, 2012). No disagreements were identified but the peer debriefing process was used to clarify names of sub-themes and inform 
descriptions for the write-up of the findings. Respondent validation was not conducted as, based on the nature of the project, the reflections were de-identified prior to the research team receiving them. Finally, three of the investigators read all of the reflections and extracted illustrative quotes corresponding to the core elements of the Interprofessional Capability Framework.

\section{Results}

The results indicate that aligning the Interprofessional Capability Framework with the learning experiences has influenced students' development (at a novice level) of the key elements of the Framework. For example, 'Client-centred' was the most frequently coded theme within the students' reflective papers, followed by Collaboration, Team Function, and Quality Care. This demonstrates the weighting given to the central aspects of the Interprofessional Capability Framework (see Table 1). The achievement (as evidenced below) of the key interprofessional capabilities outlined in the framework is significant, in that it indicates the attainment of important graduate capabilities, which typically are not well embedded into curricula. According to Knight and Yorke (2002) curricula tends to pay little attention to personal qualities and self-theories which are crucial to employability as they underpin the ability to persist in the face of conflict and failure, as well as the disposition to use initiative and get things done. Results from this study indicate that students were demonstrating novice level ability in Communication, Team Function and Conflict Resolution (Understanding and Skills). More importantly, however, these first year health science students also demonstrated evidence of capabilities related to Role Clarification (Efficacy beliefs and self-theories) and Reflection (Metacognition) at novice level. Knight and Yorke (2002) clearly view the graduate capabilities linked to Efficacy and Metacognition as more complex capabilities and essential to employability. Knight and Yorke (2002) argue that including Efficacy and Metacognition development in curricula leads to more employable graduates who are less fixed in their attitudes, are malleable, and able to commit to life-long learning. This approach is consistent with interprofessional education-as conceptualised by the Interprofessional Capability Framework at Curtin-which sees the attainment of interprofessional capabilities as part of a continuum of development. Evidence of year one student achievement of the interprofessional capabilities is provided below and aligned with the USEM model (in parenthesis).

\section{Client-Centredness (Understanding)}

Client-centred service is the central principle of the Interprofessional Capability Framework and it is expected that novice level collaborative workers will acknowledge the need to be client-centred in providing safe and high quality service/care (Brewer, 2011, p. 6). Hobbs' (2009) review of the literature evidences that client-centredness is a multidimensional concept, and different dimensions of the concept were demonstrated in students' reflections. At the most simple level, students' understandings of the meaning of client-centredness referred to a focus on the client, as opposed to a focus on the service or service-provider.

Client-centred is giving them a high quality and safe health services. It is doing what is best for them and providing them with the best we can ...

... A patient centred practice for me means that the health care system should work for the patient, instead of the patient having to work out the health care system.

Some students' reflections evidenced an understanding of the importance of respecting each client as an individual, with attention to their unique needs.

I now realise how much we perceive health practice as a 'cook book' or a certain way of doing things which completely ignores differences and subtleties in clients.

Brewer, M., Flavell, H., Davis, M., Harris, C. \& Bathgate, K. (2014). Ensuring health graduates' employability in a changing world: Developing interprofessional practice capabilities using a framework to inform curricula. Journal of Teaching and Learning for Graduate Employability, 5(1), 29-46. 
I ... not only need to listen to them but also understand their meanings and what they want.

Some students recognised that part of working with each client as an individual required health workers to view clients holistically, for example:

... not only consider the patient or client's physical health, but their mental and emotional health.

Others recognised the importance of the client's background and unique characteristics, including culture, for example:

Client-centred care is the care of a patient with strong consideration regarding their cultural traditions, personal experiences and morals and in the long run following a course of treatment that will be most beneficial to the patient.

I need to understand what their cultural values are, to ensure they feel safe and comfortable.

A final dimension of the concept of client-centredness referred to the client being an active participant in the decision making and service-process, as evidenced by comments such as:

... making the client part of the healing process so that we can stop having the attitude that we know what is best for the client.

... the client-centred service ideology has taught me how important it is for clients to not only have a team of professionals that are willing and able to talk to each other and discuss options but that the patient is also an integral part of the team.

Being a good professional doesn't just mean dispensing your expert opinion and having it taken as an order ... Working with clients can be just as important as working with other professionals.

As a health professional it is important to form a partnership with the client and help guide them and inform them of options so that they can make the best decision for themselves.

Our job as a health professional is to work in partnership with our client to provide a service or care that is purely client-centred ... sometimes in reality what we think what is in best interest for the patient might go against what they think is best for them.

Although the student statements quoted above provide evidence of their understanding of client-centred care, they also imply an element of metacognition through demonstration of a self-awareness of their professional identity formation and its potential impact on their role in health service delivery. For example, several statements above imply a self-awareness of, or critical reflectiveness about, their traditional professional culture which places the health provider as 'expert' often at the expense of the client's input into decision making.

\section{Collaborative practice capabilities}

Communication (Skills)

At the end of the undergraduate year, novice collaborative workers are expected to demonstrate developing skills in effective listening and oral and written communication skills, to respect others, and to make a contribution to team discussions (Brewer, 2011). 
Many students recognised the importance of good communication skills to their team work in the classroom and explicitly referred to the importance of appropriate communication for facilitating and demonstrating respect for others.

I learnt that communicating effectively is necessary to establish trust, to show respect to others and set up productive relationships with people.

There was also evidence from students' reflections of their skill development and recognition of the importance of confidence when participating in group discussions.

Working cooperatively with other people who are from different health domains has given me the skills to work as a group, allowing me to build my own confidence in contributing to group discussions.

... it has also made me realise that I am not confident enough. I need to speak louder when in a group and not just let others make the decisions. If I am going to have to work in a team in the future, I need to start participating more strongly now.

The cultural diversity of the cohort provided rich authentic learning opportunities related to intercultural communication and this was highlighted as a particularly valuable learning experience as well as a key challenge for students.

Being put into teams also challenged my communication skills ... being in a group with others who did not speak English as a first language challenged me to listen to myself speak and often reword my jumble so that it made sense to someone other than myself. ... I would like to continuously improve my communication skills for dealing with a variety of people different to myself.

The experience of teamwork in the classroom highlighted to students the importance of both verbal and non-verbal communication. In particular, one student commented on the importance of appreciating non-verbal aspects of communication.

...there are many verbal and non-verbal cues that can dramatically affect the way you communicate with your co-workers and patients. This made me think about how much of communication is non-verbal, which a lot of is done subconsciously...

Some students' reflections extended beyond their learning in the classroom to demonstrate their appreciation of the importance of effective communication skills in the workplace for effective teamwork and ultimately high quality client care/service.

...addressing the issues in a professional manner allows for better communication between the other health professionals ... and helps to avoid any misunderstandings and conflict that may arise if addressed in a non-professional manner.

... the chain to a client's recovery is not restricted to each health professional's consultation but also the effective communication between each health professional, a lack of communication resulting in breaking the chain and adversely affecting the client.

Communication is vital in order for an interprofessional team to be successful. If there is a lack of communication skills in a team it will affect the client's care ... 
Brewer (2011) described novice-level capabilities in team functioning as being able to describe the process of group/team development, participating in the exchange of knowledge and shared decision-making, and demonstrating effective teamwork skills including respecting team ethics. As discussed earlier, students' reflections highlighted the close relationship between communication skills and team function. Many students reflected on the importance of good teamwork during their university experience, as well as an appreciation of their teamwork experiences as a microcosm of future teamwork in the workplace.

Many students referred to important elements of forming and working as a functional group, including respect, acknowledging differences of opinion and individual strengths and weaknesses, for example:

...from the beginning we were open with each other about our own strengths and weaknesses and were willing to complement each other so as to establish functional roles for each of us.

I found that while working in these teams, communication and respect are essential, as we all study different courses, have different ethics and knowledge, we learnt to work together and resolve issues as if we were health professionals in an interprofessional team.

... by accepting or acknowledging everyone's opinion you can avoid any form of conflict and misunderstanding within the group.

The importance of all members' contributions for effective teamwork was highlighted in the following student's comment:

In our team we needed everyone to put in 110 percent, as we will in our future careers. As a health professional, being in control of people's lives and well-being it isn't okay to put in half the effort.

\section{Conflict resolution (Understanding)}

Positive and constructive conflict resolution is noted in the Interprofessional Capability Framework as an important collaborative practice capability. Novice-level collaborative workers are expected to be able to describe potential sources of conflict within interprofessional teams and identify suitable strategies to avoid or address conflict as well as to employ effective communication skills to promote positive interactions within the team (Brewer, 2011). Issues related to this element of the framework were mentioned the least frequently by the students. However, some students demonstrated knowledge of factors that can contribute to conflict within teams, for example:

...conflict among teamwork can be easily avoided if each health professional is aware of the factors that could cause conflict, such as power, communication and goal differences ....

Many students referred to the importance of good communication and teamwork skills as important for avoiding and resolving conflict, for example:

I have learnt from this experience that there is an existence of power struggles and different goals and it requires the acceptance that we all have different expertise and skills 
Other students referred to the importance of retaining a focus on the client/servicerecipient(s) in order to facilitate resolution of issues. One student referred to a real-life application of a strategy learned during his/her coursework experience in terms of seeking assistance from a supervisor or manager if team members are not able to resolve a conflict between themselves.

A real world example of when I would later use this skill is if perhaps I have an issue with a co-worker, if we try everything and still can't resolve it between ourselves I would have to go to the supervisor/management above us.

Role clarification (Efficacy beliefs and self-theories)

According to the Interprofessional Capability Framework, novice-level capabilities related to role clarification include demonstrating a developing knowledge of one's own and other professions and effectively communicating their point of review (Brewer, 2011). There is evidence that interprofessional education can provide a very helpful context for clarifying one's own professional role in collaboration with others from different professions (Pirrie, Hamilton \& Wilson, 1999) and this was supported by students' reflections, for example:

When I was explaining why I chose to do nursing to other members, I thought it was a really worthwhile activity, because it helped clarify my thinking and learned more about myself in the process.

There was significant evidence of students' demonstrating capabilities in role functioning that exceeded novice-level expectations and approached the intermediate level capability of demonstrating and understanding the importance of role clarification for client care/service provision (Brewer, 2011). This is exemplified by one students' reflection on the analogy between the experience of a group assignment and a workplace team task:

Role clarification also showed important when preparing for our oral presentations because if that didn't happen, some things may not have been done and others would have been done multiple times. This reflects the health workforce as all tasks need to be completed once and to the greatest ability possible.

One student also related role clarification to ethical practice, which represented a sophisticated reflection for a novice-level student.

The exercise also reinforced the importance of not performing tasks outside my scope of practice as this can be easily avoided and can be highly dangerous.

\section{Reflection (Metacognition)}

Novice-level capability in reflection is characterised by reflecting on one's own contribution to teamwork as well as on one's own development of interprofessional competencies (Brewer, 2011). Many students' reflections exemplified the attainment of this capability by demonstrating an awareness of the benefits of interprofessional education and their own strengths, weaknesses and areas for development.

I used to assume that ... being a good health professional meant ... knowing what is best for the patient and help them. After what I have learnt, my assumption was incorrect.

It made me question, how well do I work in a team environment? I found perhaps my strength was that I could easily help organise my group members, however a weakness was trying to find the line between talking change and also allowing everyone to have equal input 


\section{Collaborative practice and client-centredness for client-safety and quality}

Many students' reflections indicated that upon commencing their university course, they were focused on their chosen course/career and had not considered the broader context of the environment in which they would engage in professional practice. Working in interprofessional teams during the unit had opened their eyes to the importance of collaborative practice for client-centred service/care:

Working with other professionals from different fields simply wasn't something that had occurred to me. However I can see how integral it is in healthcare fields and how important it is for so many professional fields.

Several students showed a sophisticated level of reflection about their learning, related to collaborative practice capabilities, by explicitly acknowledging how the elements of the framework come together to enhance service provision/client care.

It is easy to see how things can go wrong with this type of health care system and it is a much safer and more effective system if health professionals work together. In saying that, it is also important to include the patient in this team so they are empowered and play a role in the decision making.

I think the most important thing I learnt in this unit was the need to develop inter-professional relationships. ...because if the health professionals are not communicating then the patients may not be getting the best treatment for them as an individual and this all ties back to the idea of client-centred care.

\section{Limitations}

Although the study had a reasonable response rate of 25.6 percent and included students from all of the Faculty's seven schools, due to the timing of the study most of the students were predominately from two programs of study: the generic Health Sciences degree and Nursing. Consequently, the results show greater development of Team Function, Collaboration, Communication, and less on Role Clarification and Conflict Resolution. A lack of emphasis on Role Clarification is not surprising as students were in their first semester of study in their first year with many undertaking a general health science course and hence were not aligned with a specific health profession. Class activities were directed toward building teams and developing communication skills to connect students to the course, university, other students and support student retention. This emphasis on connection and cohesion within the context of the first year experience combined with the difficulty many people have in recognising the value and normality of conflict likely explains why conflict resolution was the least mentioned capability.

Students who participated in the study self-selected, which had the potential to influence the findings; it may well be that students who were most engaged in their study felt more confident in submitting their reflective journal which raises questions about how effective the unit had been in achieving the desired outcomes for less engaged students.

\section{Discussion}

Across the 105 participants, there was certainly evidence of the attainment of novice level interprofessional capabilities. Students' reflections demonstrated varying levels of sophistication with some referring directly to their experiences in the classroom, some referring to the Interprofessional Capability Framework more abstractly, and some showing evidence of how their classroom experiences will be relevant to their future workplace practice. Given that they were first semester, first year students and thus their ability for reflective practice emergent and their experience and understanding of health practice 
limited, the evidence of novice level interprofessional capabilities suggests that alignment of the interprofessional first year curriculum with the Interprofessional Capability Framework is delivering the desired outcomes: that is, students are beginning their journey to developing the interprofessional practice capabilities identified as crucial for future health workers.

Interprofessional socialisation exposes students to the roles and functions of other professions and assists with the development of their professional and interprofessional identity. Despite the increasing acceptance of the value of this socialisation a review of curricula in Canada (Arndt, King, Suter, Mazonde, Taylor \& Arthur, 2009) found little evidence of this being embedded with any consistency. In keeping with the Canadian review recommendations, this foundational unit embeds significant interprofessional socialisation enabling students to begin building their interprofessional capabilities early in their training. In addition to role clarification, early interprofessional socialisation has been identified as a mechanism to improve communication, respect and trust, and reduce prejudice and negative attitudes (Barr, Koppel, Reeves, Hammick \& Freeth, 2005).

The literature shows that early embedding of interprofessional education is, in itself, not sufficient. Learning experiences must be aligned with good practice in interprofessional education curriculum design. The Foundations of Professional Health Practice unit captures all three elements of the accepted definition of interprofessional education: about, from and with, by utilising trained co-teachers from different professions, providing a range of activities including case-based discussions, joint projects and presentations (Bainbridge \& Wood, 2013). A strong emphasis on adult learning theory in the unit's implementation ensures that cooperative, collaborative, reflective and socially constructed learning takes place within each weekly workshop (Barr, 2012).

The Foundations of Professional Health Practice unit provides a basis on which other elements of Curtin's interprofessional education curriculum are built and students are able to draw on the interprofessional connections established in first year. Students are provided with opportunities to apply their emerging understanding of client-centred service, safety and quality in health, and collaborative practice in a range of other experiences including interprofessional case-based workshops (Brewer, Tucker, Irving \& Franklin, 2014) and interprofessional fieldwork placements (Brewer \& Jones, 2014). Reflection is an integral competency for professional practice (Wald, Borkan, Scott Taylor, Anthony \& Reis, 2012) and particularly relevant to interprofessional education where students need to reflect to effectively learn 'with, from and about each other'. According to Zarezadeah, Pearson \& Dickinson (2009) reflection on the role and importance of 'others' leads to better understanding and a more reinforced acquaintance, which, in turn, lessens prejudice and breaks stereotypes (p. 8). Whilst Foundations of Professional Health Practice provides a starting point, more opportunities to develop reflective skills are recommended with greater guidance on reflective practice provided in an ongoing, scaffolded manner throughout the curriculum. It is thus recommended that efforts be made to fully vertically integrate authentic interprofessional learning experiences for all health science students to deliver Curtin's vision of health science graduates having the collaborative practice capabilities to deliver safe, effective health services. Further research is also required to determine whether this interprofessional curriculum is achieving the desired collaborative practice capabilities (Zarezadeah et al., 2009).

\section{Conclusion}

Curtin's Interprofessional Capability Framework can function effectively as a curriculum design tool through its alignment with the learning outcomes, experiences and assessments to assist students to develop an understanding of interprofessional collaboration. As described in Brewer and Jones (2013) the framework guided the constructive alignment of this foundational unit (Biggs, 2003); the learning outcomes included key elements of the 
framework, the learning experiences were designed to meet these outcomes, and the assessment utilising a reflective paper was designed to measure the impact of the unit on the student's development of novice interprofessional capabilities.

Beyond their application to the health professions these results indicate that the unit aligns well with Yorke and Knight's (2002) USEM model of employability with students evidencing all four elements of this model within their reflective journals. This early focus on the higher order graduate capabilities of Efficacy and Metacognition should provide students with a foundation on which to continue their journey to employability in its broadest sense; that is, beyond discipline knowledge.

\section{Acknowledgements}

The authors would like to acknowledge the contribution of Candice Leeder and Lorenz Wolf for the NVivo ${ }^{\odot}$ analysis, and Emma Penman for assistance in presenting the analysis. 


\section{References}

Arndt, J., King, S., Suter, E., Mazonde, J., Taylor, E. \& Arthur, N. (2009). Socialization in Health Education: Encouraging an integrated interprofessional socialization process. Journal of Allied Health, 38, 18-23.

Bainbridge, L., Nasmith, L., Orchard, C. A. \& Wood, V. (2010). Competencies for interprofessional collaboration. Journal of Physical Therapy Education, 24(1), 6-11.

Bainbridge, L. \& Wood, V. I. (2013). The power of prepositions: A taxonomy for interprofessional education. Journal of Interprofessional Care, 27(2), 131-136.

Barr, H. (1998). Competent to collaborate: Towards a competency-based model for interprofessional education. Journal of Interprofessional Care, 12(2), 181-187.

Barr, H. (2002). Interprofessional education today, yesterday and tomorrow. Commissioned by the Learning and Teaching Support Network of the Health Sciences and Practice from the UK Centre for the Advancement of Interprofessional Education. London: CAIPE.

Barr, H. (2012). Toward a theoretical framework for interprofessional education. Journal of Interprofessional Care, 27(1), 4-9.

Barr, H., Koppel, K., Reeves, S., Hammick, M. \& Freeth, D. (2005). Effective interprofessional education: Argument, assumption and evidence. Oxford: Blackwood.

Barrett, J., Curran, V., Glynn, L. \& Godwin, M. (2007). CHSRF Synthesis: Interprofessional collaboration and quality primary health care. C. H. S. R. Foundation (Ed.) Retrieved from http://www.cfhi-fcass.ca/Migrated/PDF/SynthesisReport_E_rev4_FINAL.pdf

Barrie, S. (2012). A research-based approach to generic graduate attributes policy. Higher Education Research \& Development, 31(1), 79-92.

Barrie, S., Hughes, C. \& Smith, C. (2009). The National Graduate Attributes Project: Integration and assessment of graduate attributes in curriculum. Sydney: Australian Learning and Teaching Council.

Bathgate, K. \& Harris, C. (2012). The impact of eLearning tools on the interprofessional learning experience in a first year foundations health unit. In A. Herrington, J. Schrape \& K. Singh (Eds.), Engaging students with learning technologies (pp. 209-222). Perth, Australia: Curtin University.

Bazeley, P. (2007). Qualitative data analysis with NVivo qualitative project book. Thousand Oaks, California: Sage.

Boyd, E. M. \& Fales, A. W. (1983). Reflective learning: Key to learning from experience. Journal of Humanistic Psychology, 23(2), 99-117.

Brewer, M. (2011). Curtin University's Faculty of Health Sciences Interprofessional Capability Framework. Perth: Curtin University. Retrieved from http://healthsciences.curtin.edu.au/faculty/ipe_publications.cfm

Brewer, M. \& Jones, S. (2013). An interprofessional practice capability framework focusing on safe, high quality client-centred health service. Journal of Allied Health, 42(2), e45-49.

Brewer, M. \& Jones, S. (2014). A university-community engagement and leadership model. In D. Forman, M. Jones \& J. Thistlethwaite (Eds.), Leadership development for interprofessional education and collaborative practice (pp. 85-104). Basingstoke, Hampshire and New York: Palgrave MacMillan.

Brewer, M., Tucker, B., Irving, L. \& Franklin, D. (2014). The evolution of faculty-wide interprofessional education workshops. In D. Forman, M. Jones \& J. Thistlethwaite (Eds.), Leadership development for interprofessional education and collaborative practice (pp. 206-227). Basingstoke, Hampshire and New York: Palgrave MacMillan.

Bridgstock, R. (2009). The graduate attributes we've overlooked: Enhancing graduate employability through career management skills. Higher Education Research \& Development, 28(1), 31-44. 
Biggs, J. (2003). Aligning teaching and assessing to course objectives. Paper presented at Teaching in Higher Education: New Trends and Innovations. Portugal: University of Aveiro.

Bryman, A. (2012). Social research methods ( $4^{\text {th }}$ ed.). New York: Oxford UP.

Carpenter, J. (1995). Doctors and nurses: Stereotypes and stereotype change in interprofessional education. Journal of Interprofessional Care, 9(2), 151-161.

Clark, P. G. (2009). Reflecting on reflection in interprofessional education: Implications for theory and practice. Journal of Interprofessional Care, 23(3), 213-223.

Colyer, H., Helme, M. \& Jones, I. (2005). The theory-practice relationship in interprofessional education. London: HEA, (Occasional paper No 7).

Cooper, H., Spencer-Dawe, E. \& McLean, E. (2005). Beginning the process of teamwork: Design, implementation and evaluation of an inter-professional education intervention for first year undergraduate students. Journal of Interprofessional Care, 19(5), 492-508.

Coster, S., Norman, I., Murrells, T., Kitchen, S., Meerabeau, E., Sooboodoo, E. \& d'Avray, L. (2008). Interprofessional attitudes amongst undergraduate students in health professions: A longitudinal questionnaire survey. International Journal of Nursing Studies, 45(7), 10321041. doi:10.1016/j.jjurstu.2008.02.008

Creswell, J. W. (2012). Educational research: Planning, conducting, and evaluating quantitative and qualitative research ( $4^{\text {th }}$ ed.). Boston: Pearson.

Curran, V., Casimiro, L., Banfield, V., Hall, P., Lackie, K., Simmons, B., ...Oandasan, I. (2008). Research for interprofessional competency-based evaluation (RICE). Journal of Interprofessional Care, 23(3), 297-300.

de la Harpe, B., Radloff, A., Scoufis, M., Dalton, H., Thomas, J., Lawson, A., ... Girardi, A. (2009). The $B$ factor project: Understanding academic staff beliefs about graduate attributes. Final Report. Surry Hills: Australian Learning and Teaching Council.

Epstein, R. M. \& Hundert, E. M. (2002). Defining and assessing professional competence. Journal of American Medical Association, 287(2), 226-235.

Eraut, M. (1998). Concepts of competence. Journal of Interprofessional Care, 12(2), 127139.

Findlay, N., Dempsey, S. \& Warren-Forward, H. (2010). Validation and use of the Newcastle Reflective Analysis Tool: A three-year longitudinal study of RT students' reflective journals. Reflective Practice, 11(1), 83-94.

Forte, A. \& Fowler, P. (2009). Participation in interprofessional education: An evaluation of student and staff experiences. Journal of Interprofessional Care, 23(1), 58-66.

Frank, J. R., Mungroo, R., Ahmad, Y., Wang, M., De Rossi, S. \& Horsley, T. (2010). Toward a definition of competency-based education in medicine: A systematic review of published definitions. Medical Teacher, 32(8), 631-637.

Hean, S., Craddock, D. \& Hammick, M. (2012). Theoretical insights into interprofessional education. Medical Teacher, 34, 158-160.

Hobbs, J. L. (2009). A dimensional analysis of patient-centered care. Nursing Research, 58(1), 52-62.

Interprofessional Education Collaborative Expert Panel. (2011). Core competencies for interprofessional collaborative practice: Report of an expert panel. http://www.aacn.nche.edu/education-resources/IPECReport.pdf

Karban, K. \& Smith, S. (2006). Developing critical reflection within an interprofessional learning programme. Leeds: Leeds Metropolitan University.

Knight, P. T. \& Yorke, M. (2002). Employability through the curriculum. Tertiary Education and Management, 8(4), 261-276.

Krause, K-L., Barrie, S., Scott, G., Sachs, J. \& Probert, B. (2012). Mapping learning and teaching standards in Australian higher education: An issues and options paper. Paper 
presented at the Higher Education Evaluation Roundtable 2012. Sydney: University of Western Sydney.

Mann, K. V., Gordon, J. \& MacLeod, A. (2009). Reflection and reflective practice in health professions education: A systematic review. Advances in Health Sciences Education, 14, 595-621.

McNair, R. (2005). The case for educating health care students in professionalism as the core content of interprofessional education. Medical Education, 39, 456-464.

Moon, J. A. (2013). Reflection in learning and professional development: Theory and practice. Hoboken: Taylor and Francis.

Morison, S., Johnston, J. \& Stevenson, M. (2010). Preparing students for interprofessional practice: Exploring the intra-personal dimension. Journal of Interprofessional Care, 24(4), 412-421.

Oliver, B. (2011). Assuring graduate outcomes. ALTC Good Practice Reports. Strawberry Hills, NSW: Australian Learning and Teaching Council.

Pirrie, A., Hamilton, S. \& Wilson, V. (1999). Multidisciplinary education: Some issues. Educational Research, 41(3), 301-314.

Precision Consulting. (2007). Graduate employability skills. Melbourne: Business, Industry and Higher Education Collaboration Council.

Reeves, S., Fox, A. \& Hodges, B.D. (2009). The competency movement in the health professions: Ensuring consistent standards or reproducing conventional domains of practice? Advances in Health Sciences Education, 17 June. doi: 10.1007/s-10459-0099166-2

Reeves, S., Tassone, M., Parker, K., Wagner, S. J. \& Simmons, B. (2012). Interprofessional education: An overview of key developments in the past three decades. Work 2012, 41, 233-245.

Reeves, S., Zwarenstein, M., Goldman, J., Barr, H., Freeth, D., Koppel, I. \& Hammick, M. (2010). The effectiveness of interprofessional education: Key findings from a new systematic review. Journal of Interprofessional Care, 24(3), 230-241.

Ryan, G. W. \& Bernard, R. H. (2003). Techniques to identify themes. Field Methods, 15(1), 85-109.

Stephenson, J. (1994). Capability and competence: Are they the same and does it matter? Capability, 1(1), 3-4.

Wackerhausen, S. (2009). Collaboration, professional identity and reflection across boundaries. Journal of Interprofessional Care, 23(5), 455-473.

Wald, H. S., Borkan, J. M., Scott Taylor, J., Anthony, D. \& Reis, S. P. (2012). Fostering and evaluating reflective capacity in medical education: Developing the REFLECT rubric for assessing reflective writing. Academic Medicine, 87(1), 41-50.

Walsh, C. L., Gordon, M.F., Marshall, M., Wilson, F. \& Hunt, T. (2005). Interprofessional capability: A developing framework for interprofessional education. Nurse Education in Practice, 5(4), 230-237.

Wood, V., Flavell, A., Vanstolk, D., Bainbridge, L. \& Nasmith, L. (2009). The road to collaboration: Developing an interprofessional competency framework. Journal of Interprofessional Care, 23(6), 621-629.

World Health Organisation. (2010). Framework for action on interprofessional education and collaborative practice. WHO/HRH/HPN.

Yorke, M. (2006). Employability in higher education: What it is - what it is not. Learning and Employability Series. London: Higher Education Academy.

Zarezadeah, Y., Pearson, P. \& Dickinson, C. (2009). A model for using reflection to enhance interprofessional education. International Journal of Education, 1(1), 1-18. 